Hydrology and Earth System Sciences, 8(6), 1090-1102 (2004) C EGU

\title{
Groundwater recharge and capillary rise in a clayey catchment: modulation by topography and the Arctic Oscillation
}

\author{
Thomas M. Schrøder ${ }^{1}$ and Dan Rosbjerg ${ }^{2}$ \\ ${ }^{1}$ Jet Propulsion Laboratory, California Institute of Technology, Pasadena, USA \\ ${ }^{2}$ Environment \& Resources DTU, Technical University of Denmark, 2800 Kongens Lyngby, Denmark \\ Email for corresponding author: dr@er.dtu.dk
}

\begin{abstract}
The signature left by capillary rise in the water balance is investigated for a $16 \mathrm{~km}^{2}$ clayey till catchment in Denmark. Integrated modelling for 1981-99 substantiates a 30\% uphill increase in average net recharge, caused by the reduction in capillary rise when the water table declines. Calibration of the groundwater module is constrained by stream flow separation and water table wells. Net recharge and a priori parameterisation has been estimated from those same data, an automatic rain gauge and electrical sounding. Evaluation of snow storage and compensation for a simplified formulation of unsaturated hydraulic conductivity contribute to a modelling of the precipitation-runoff relation that compares well with measurements in other underdrained clayey catchments. The capillary rise is assumed to be responsible for a $30 \%$ correlation between annual evapotranspiration and the North Atlantic Oscillation. The observed correlation, and the hypothesis of a hemispherical Arctic Oscillation linking atmospheric pressure with surface temperature, suggests that modelled evapotranspiration from clayey areas is better than precipitation records for identifying the region influenced by oscillation.
\end{abstract}

Keywords: catchment modelling, MIKE SHE, capillary rise, degree-day model, climate

\section{Introduction}

During the ice ages, glacial thrusts formed the surface of most of the present day cold and temperate areas. The extensive mixing makes glacial till units appear clayey, even for minor clay contents. Generally, the permeability of till is small. When modelling groundwater recharge in those regions, for the cumbersome description of the tortuous circulation inside clay till deposits (Hinton et al., 1993), a 'black box' aquitard that passively transfers atmospheric forcing down to confined aquifers of interest for abstraction (Gerber and Howard, 2000) is usually substituted. Hillslope models detail the flow through the aquitards in a balance between unsaturated flow and stream flow (Wigmosta and Burges, 1997). Field experience, in conjunction with these local models, has paved the way for integrated models that supposedly account for all processes near the surface, including tension-driven flow. Potentially, the uncertainty in recharge estimation can be reduced dramatically (Lerner et al., 1990).
Solar radiation drives photosynthesis and dries the soil. Upward flow from the water table is triggered once moisture depletion has reached the groundwater body. This feedback to evapotranspiration is termed capillary rise. Laboratory studies (Malik et al., 1989) and field studies undertaken in semiarid areas (Prathapar and Meyer, 1993) have verified that the process occurs in clay soils at water table depths of several metres. The standard procedure in groundwater abstraction modelling, however, has been to ignore the capillary rise, but this widens the 'scalar gap' between model parameters at basin scale and their value in studies of nearsurface processes.

Statistics combining hill slope and basin models in steadystate show that net recharge increases uphill because a deeper water table dampens the capillary rise (Levine and Salvucci, 1999). The purpose of the present paper is to apply an integrated model in a dynamic validation of both the topographical dependence of net recharge and the effect on the water balance of the Arctic Oscillation. In the latter case, 
the hypothesis is that modelling of catchment evapotranspiration can supplement precipitation records in tracking the spatial extent of inter-annual barotropic oscillation. This may contribute to the debate on the mechanism behind the North Atlantic Oscillation.

Parameterisation of flow processes near the surface is explored in a fully underdrained catchment with wells. Here, the tile drain outflow to the stream integrates the portion of recharge that does not replenish the regional aquifer, while the wells monitor the water table rise indicating recharge. The bridging of the aforementioned scalar gap by these measurements, combined with the notion that recharge varies less than soil parameters, makes it plausible to map net recharge from these measurements and, subsequently, use the map to constrain an optimisation of groundwater parameters in a catchment model. In the optimisation, the substitution of atmospheric flux with the flux at the bottom of the unsaturated zone prevents the parameters in question from interfering non-linearly with recharge through the retention curve. As a result, the parameter correlation will also become more linear and thus easier to interpret.

Meticulous fieldwork and modelling have been conducted to provide a realistic estimate of the net recharge (Schrøder, 2003). In that work, two years of daily net recharge in six terrain intervals was unfolded towards the summer regime, when the capillary rise reaches its maximum, using a priori parameters. In brief, the water table data determine the wet area contributing to tile drain outflow. Stream flow separation confirms that net recharge in this terrain interval equals the rainfall of that day. The time constant for tile drain outflow is found from the rate at which the terrain interval shrinks after rain. Results of slug tests in the wells are linked to unsaturated characteristics in a soil database using the rise of the water table during a storm. Preferential conduits in the weathered zone are accounted for by an anisotropy ratio determined from the head potential field in a transect perpendicular to a single drain line and outflow according to the drain time constant. Linkage to the slug test result enables modelling of net recharge at each of the wells belonging to the complementary dry area. It is of the utmost importance for an unbiased reproduction of capillary rise that the boundary condition between the modelled vadose zone and groundwater complies with the hydrostatic condition, i.e. that tension equals height above the water table in the range of the water table fluctuation. Otherwise, the transition towards free drainage would require the assumption of a partially horizontal flow pattern with a host of geometric parameters to calibrate. The hydrostatic condition has been validated by inserting observed water table depths and soil characteristics found by slug tests in a steady-state model for unsaturated flow. Finally, the variable source concept used to quantify net recharge in the wet area is extended to every terrain interval - regardless of state. The a priori applied Hydrus1D and 2D models are similar to the integrated $3 \mathrm{D}$ model in the equations of flow, but different in the sink for drainage flow, in the formulation of unsaturated hydraulic conductivity and in the merging of unsaturated strata.

Following a description of the study catchment and the parameterisation of snow storage, the integrated model is explained. Then, the groundwater module is optimised using a priori parameters and a fixed net recharge, and the change in formulation of unsaturated conductivity from the a priori recharge modelling is examined. The model is run over 19 years to evaluate the fit to measured runoff, the correlation between terrain level and average net recharge, and the correlation between the Arctic Oscillation and annual evapotranspiration.

\section{Study Catchment}

Harrested catchment is situated in Denmark south of the town Slagelse in rural south-western Zealand (Fig. 1a). The area upstream of the main discharge gauging station 5602 is $16.01 \mathrm{~km}^{2}$ with the relief $14-93 \mathrm{~m}$ above mean sea level, as sketched in Fig. 1b. Between 95 and $98 \%$ of the soil has been classified as clay till. In September 1997, two years of monitoring began around the farm Idagård with 11 wells that recorded the water table depth. The wells are representative of two-thirds of the catchment, in terms of terrain level. The automatic tipping-bucket rain gauge at Idagård is, like the daily emptied rain gauge at Antvorskov, corrected for wind and wetting following Allerup and Madsen (1980), while stream flow is recorded at the discharge gauging weirs $A, B$ and $C$. Global radiation, temperature, wind and humidity recorded at Flakkebjerg underlie a modified Penman estimate of the daily potential evapotranspiration (Mikkelsen and Olesen, 1991).

\section{HYDROGEOLOGY}

The confined regional aquifer is formed by glaciofluvial sediments, with an overburden of glacial till and almost no seepage through the tertiary clay underneath (Christensen, 1994). The unconfined overburden comprises a terminal till in the ridge running along the northern and western flank of the catchment, a lodgement till deposited uniformly by a later thrust and a flow till that gave the northern ridge an irregular topography during the final melt-off. The regional water divide coincides with the northern ridge and the groundwater is considered to cross the catchment boundary via the confined aquifer only. Both the aquifer level and the 


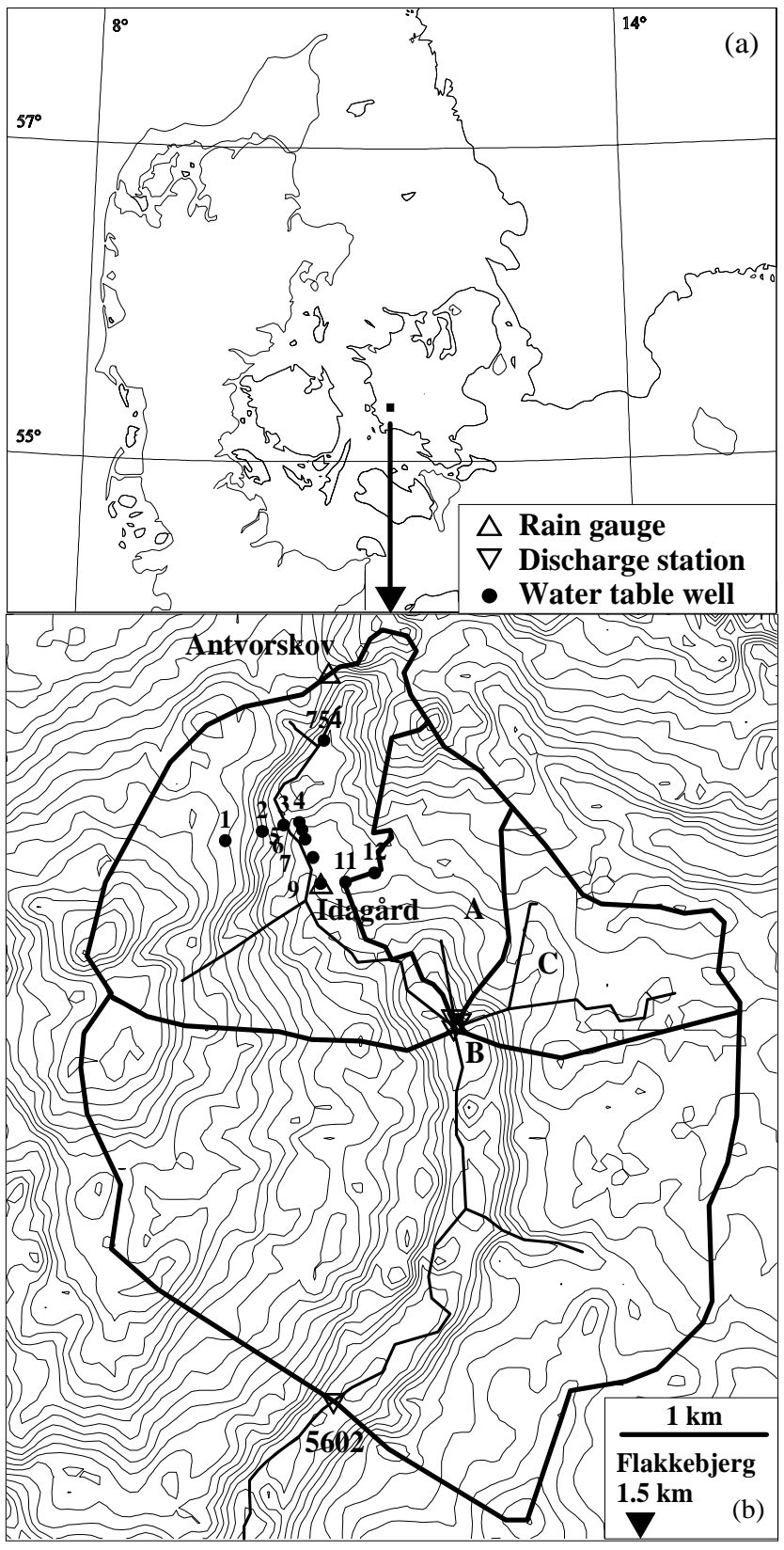

Fig. 1. (a) Location of study catchment, with (b) terrain contours in $2.5 \mathrm{~m}$ intervals and instrumentation.

hydraulic conductivity were interpolated between the wells with a combination of borehole logging, electrical sounding, and base flow modelling. Figure 2 summarises the relation between topography and the depth of the weathered strata. The wedge of reduced till represents the capillary rise that separates the water table minimum at the bottom from the visible oxidation front at the top (Schrøder, 2003).

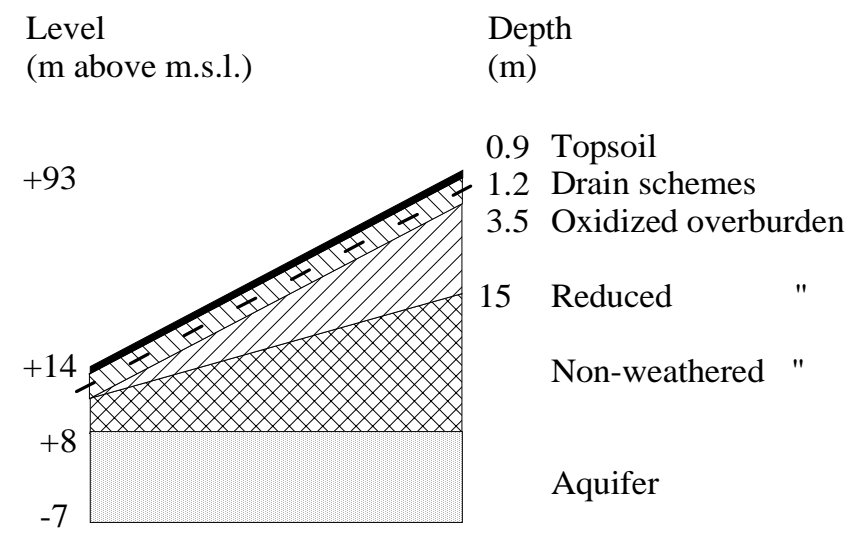

Fig. 2. Conceptual geology and depth of drain schemes.

\section{VEGETATION}

In 1991, the agricultural area constituted $99 \%$ of the catchment and had changed little over the previous six decades (Waagepetersen et al., 1991). Figure 3 shows the response in the county to the National Water Protection Act of 1987 that encouraged the sowing of crops on bare winter fields, a fallow zone around streams and restoration of wetlands. Consequently, farmland decreased somewhat and winter wheat substituted for other types of grain, primarily spring barley. Pasture and meadow around the open stream, including the small village, are modelled as permanent grass covering the lowermost $5 \%$ of the catchment. The grain crops, spring barley and winter wheat, are modelled separately. On average over the period 1981-99, spring barley occupies two-thirds and winter wheat one- third of the arable area and the slow change from one to the other has been represented by weighting the two model runs accordingly.

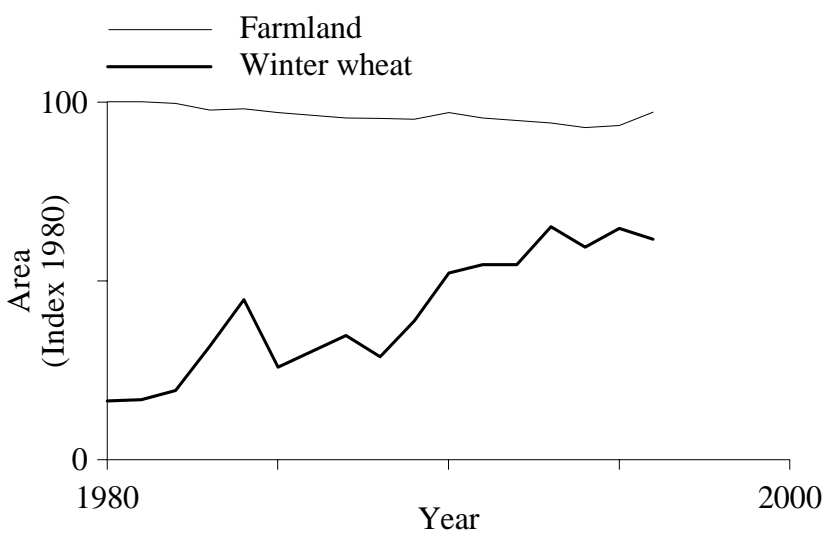

Fig. 3. Development of farmland in the county of Western Zealand, in particular how much winter wheat made up of the area covered by grain (Statistics Denmark, 1986-99). 


\section{SNOW STORAGE}

The daily emptied rain gauge at Antvorskov and the automatic rain gauge at Idagård are of the Hellmann kind. Both are aluminium fabricated with a cross inserted during winter to prevent snowdrift. While the manual gauge represents the day of precipitation, the non-heated automatic gauge records an occasional delay that is assumed to represent temporary storage as snow before infiltration. The degree-day model retards melting of new snow when the air temperature $T\left({ }^{\circ} \mathrm{C}\right)$ drops below a base $T$, , and releases infiltration $I \mathrm{~mm} \mathrm{~d}^{-1}$ ] proportional to the melt rate $D$ $\left[\mathrm{mm}^{\circ} \mathrm{C} \mathrm{d}^{-1}\right]$ when the air temperature rises above $T$ '.

$$
I=\left\{\begin{array}{ll}
0 & ; T \leq T \\
D\left(T-T^{\prime}\right) & ; T>T
\end{array},\right.
$$

Temperature records divide at midnight, while manual precipitation records divide at $8 \mathrm{am}$. The time lag is accommodated by a shift in the least erratic record, the temperature, in which the day of emptying is weighted as one-third and the previous day is weighted as two-thirds.

Analysis of hourly measurements at Flakkebjerg predicts that the error in the weighted daily temperature is random with a standard deviation of $0.6^{\circ} \mathrm{C}$. Between November 1998 and February 1999, the daily temperature ranged from -8 to $+7^{\circ} \mathrm{C}$ around an average of $+1^{\circ} \mathrm{C}$. Precipitation recorded was $257 \mathrm{~mm}$. A $2 \%$ difference in catch at the automatic gauge indicates that convective storms and sporadic snowdrift introduce only minor errors in the mass budget, so the four months are appropriate for calibration of the degree-day model.

Rango and Martinec (1995) found that the high albedo and the large liquid water content in springtime increased the melt rate from 4 to $7 \mathrm{~mm}^{\circ} \mathrm{C} \mathrm{d}^{-1}$ in windswept woodless areas, but the secondary role of solar radiation and the observation that snowfall normally melts within a few weeks in coastal areas near sea level support a constant melt rate, $D$, in the catchment. Figure 4 a shows improvement in the calibration as the melt rate goes up. The value $8 \mathrm{~mm}^{\circ} \mathrm{C} \mathrm{d}^{-1}$ is chosen because higher values lead to only a minor improvement (only for one day, a day of convective storm perhaps), and to minimise the excess above the upper limit of the $1.5-5 \mathrm{~mm}^{\circ} \mathrm{C} \mathrm{d}^{-1}$ interval expected for southern Scandinavia (Bergström et al., 1993). The lower limit of that interval represents forested areas. Figure $4 \mathrm{a}$ also shows $\mathrm{a}-1^{\circ} \mathrm{C}$ base temperature, $T$, , regardless of the melt rate. A negative value is expected in coastal areas near sea level, where overcast conditions reduce outgoing radiation during the long winter nights frequently enough to reduce the diurnal amplitude and, hence, extend the few daytime hours above the freezing point.

Figure $4 \mathrm{~b}$ shows that the record of the manual gauge resembles the record of the automatic gauge, when corrected

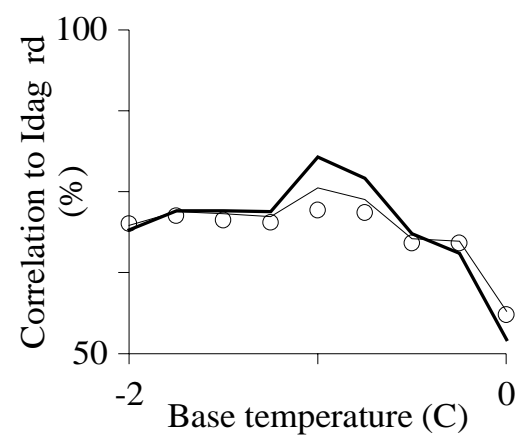

(a)

Antvorskov with melt rate $2 \mathrm{mmd}^{-1} \mathrm{C}^{-1}$

4

(b)

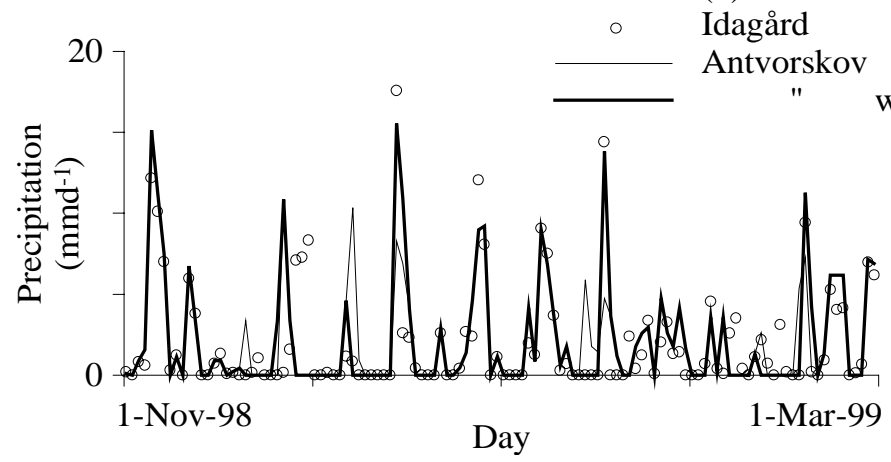

Fig. 4. (a) Base temperature and melt rate for snow storage calibrated to match Antvorskov's daily emptied rain gauge with Idågård's automatic rain gauge, and (b) underlying time series. 
for snow storage. A perfect fit is impossible because heavy showers at the time of emptying bias the peaks in early November and late December. Furthermore, precipitation over the last weekend was recorded the following Monday morning and distributed uniformly. The degree-day model retards $12 \%$ of all winter precipitation between 1981 and 1999 in the present case. This should be discernible in the runoff modelling, despite the absence of a radiation term (Rango and Martinec, 1995).

\section{Integrated model}

The adopted code MIKE SHE (DHI, 1999) has a groundwater module in which sinks for abstraction by waterworks and exchange with streams are included in Boussinesq's flow equation. Tile drains form a second sink to streams and are described as a linear reservoir, i.e. with outflow proportional to storage. The drain time constant, in the following abbreviated to drain time, accounts for drain density and soil permeability, and is taken as uniform because all discharge gauging stations indicate similar values (Schrøder, 2003).

In the catchment, the only waterworks abstracts 70000 $\mathrm{m}^{3} \mathrm{y}^{-1}$ from the stream valley. The terrain level is interpolated from digitised contour lines using block-kriging. Prior variogram analysis reveals that setting the mesh width in the quadratic model grid to $100 \mathrm{~m}$ reproduces all the digitised terrain features well. All weathered strata are merged in the groundwater module. The layer depth one to two orders of magnitude smaller than the mesh width ought to capture the vertical flow component below the water table. A single layer can also represent the confined aquifer with the seepage across the catchment boundary, whereas the non-weathered overburden has been split into six equally thick computational layers to allow for the bending of the head potential field around the stream. The boundary head of the aquifer is interpolated between deep wells inside and outside the catchment combining a spatially uniform annual trend, a constant spatial distribution and a constant seasonal oscillation. This separation is based on van der Kamp and Maathuis (1991), who observed that the head of an aquifer confined by clay reproduced the surface load as 'a giant lysimeter'.

The stream has a trapezoidal cross-section two orders of magnitude smaller than the mesh width, in compliance with the nodal representation. Exchange with groundwater is dominated by the aquifer and simplified to vertical exchange with an aquifer at finite depth (DHI, 1999). A low permeability streambed, referred to as lining, is not discernible in clay soils. The term for lining is eliminated from the exchange by being set equal to the conductivity of the overburden divided by its mean thickness. Both values have been estimated from electrical sounding (Schrøder, 2003). Stream flow is approximated as a diffusive wave, sufficient for routing daily precipitation through the short reach. Overland flow is routed as a kinematic wave to facilitate convergence in the iteration between storage above and below the water table.

\section{Groundwater module}

The low permeability overburden requires transient instead of conventional steady-state calibration (Halford, 1999). The two years with established a priori net recharge suffice because drainage flow flushes the weathered zone in the lower half of the catchment five times. Automatic calibration is conducted with a search along an objective function that accumulates the discrepancy between simulated and measured time series. First-order derivatives of each parameter against each measurement are gathered in a Jacobian matrix, and a Marquardt-Levenberg scheme inspects its eigenvectors to turn the search in the parameter space away from the steepest descent, when correlation emerges. Calibration of a Boussinesq model with this approach has been successful in the neighbouring Tude catchment (Christensen and Cooley, 1999). The adopted calibration code Pest (Doherty, 1999) allows for central difference iteration and distribution of model runs on a computer network.

Non-linearity is suppressed by $\log$ transformation of conductivity (Isaaks and Srivastava, 1989) and the drain parameterisation. The topsoil is beyond calibration because the tile drains keep the water table below it most of the time. Calibration has been narrowed to the seven parameters marked in Table 1 with two constraints. Firstly, vertical conductivity in the weathered zone is tied to its horizontal counterpart via the anisotropy ratio. Secondly, the specific yield of the non-weathered overburden is tied to that of the reduced till. The second constraint eliminates the artificial threshold in the objective function that arises if the water table falls below the weathered zone during optimisation. The initial specific yield is taken from the soil database of Carsel and Parrish (1988) according to horizontal conductivity. Inside the area contributing to drainage flow, the initial water table is set to the drain depth and outside to a depth that increases uphill with the rate of the water table minimum (Schrøder, 2003). Test runs indicate that the piezometric head field will recover from an erroneous water table within two months. Omitting the first three months of simulation in the calculation of the objective function value will therefore suffice to eliminate any impact of the initial conditions. 
Table 1. Groundwater and surface parameters from Schrøder (2003). Bold figures are subject to calibration.

\begin{tabular}{|c|c|c|c|c|}
\hline & \multicolumn{2}{|c|}{ Conductivity $\left(\mathrm{mm} \mathrm{d}^{-1}\right)$} & \multicolumn{2}{|c|}{ Storage (\%) } \\
\hline & Vertical & Horizontal & Unconfined & Confined \\
\hline Topsoil & 75 & $20 \times$ & 5.5 & 0.010 \\
\hline Oxidized overburden & $29(200)$ & $"$ & $5.0(4.9)$ & $"$ \\
\hline Reduced ～" & $0.21(0.069$ & $"$ & $0.59(0.26)$ & $"$ \\
\hline Non-weathered " & $0.78(1.2)$ & $0.78(0.19)$ & $"$ & $"$ \\
\hline Aquifer & 8600 & $1 \times$ & 37 & $"$ \\
\hline Drain time & & & $0.28 \mathrm{~d}^{-1}$ & \\
\hline Detention storage & & & $0.01 \mathrm{~m}$ & \\
\hline Stream lining & & & $10^{-11} \mathrm{~s}^{-1}$ & \\
\hline \multirow[t]{2}{*}{ Manning number } & \multicolumn{2}{|l|}{ Stream flow } & $20 \mathrm{~m}^{1 / 3} \mathrm{~s}^{-1}$ & \\
\hline & \multicolumn{2}{|c|}{ Overland flow } & $5 \mathrm{~m}^{1 / 3} \mathrm{~s}^{-1}$ & \\
\hline
\end{tabular}

In the objective function, daily means for the six water table wells are added to the runoff measured at the four discharge gauging stations. Adding more wells to further increase the ratio between measurements and free parameters would improve calibration only marginally (Duan et al., 1992). Wells 1, 2, 5, 9, 12 and 754 give the most comprehensive control of the regime at different terrain levels (Figs. 1b and 2). The linkage in the prior recharge mapping of wet area and terrain level carries over to the objective function only in terms of water table depth. The discharge series has been normalised against depth to facilitate comparison and, thereby, penalise a misfit between the area contributing to drainage flow and the area with uphill decreasing water table. Relative weights $w$ on the water table $h$ and the discharge $Q$, calculated from the number of observations $N$ and the standard deviation $\sigma$,

$$
\begin{aligned}
& w_{Q}=1 \\
& w_{h}=\frac{N_{Q}}{N_{h}} \frac{\sigma_{Q}}{\sigma_{h}}=\frac{1639}{3028} \frac{0.11 \mathrm{~mm} \mathrm{~d}^{-1}}{1.06 \mathrm{mmd}^{-1} \mathrm{~m}^{-1}}=0.06
\end{aligned}
$$

ensure equal emphasis in the combined objective function

$$
\phi=\sum_{i=1}^{N_{Q}}\left(w_{Q}\left(Q_{s i m}-Q_{o b s}\right)\right)^{2}+\sum_{j=1}^{N_{h}}\left(w_{h}\left(h_{s i m}-h_{o b s}\right)\right)^{2}
$$

where sim denotes simulation and $o b s$ observation (Carrera and Neumann, 1986). Figure 5 gives an overview of the seven calibrations carried out, each taking a different pathway from the a priori parameterisation to avoid stopping at the same threshold in the objective function, or falling into the same local minimum. The sequential calibration $(I)$ finishes the drain time first, then conductivity and then specific yield. The other calibrations keep, respectively, all parameters free $(I I)$, the drain time to the value of the second
Calibration

Average fit

Water table $(\mathrm{m})$

Discharge $\left(\mathrm{mmd}^{-1}\right)+$

Drain time $\left(\mathrm{d}^{-1}\right)$

Conductivity $\left(\mathrm{mmd}^{-1}\right)$
Oxidized horizontal

Reduced horizontal
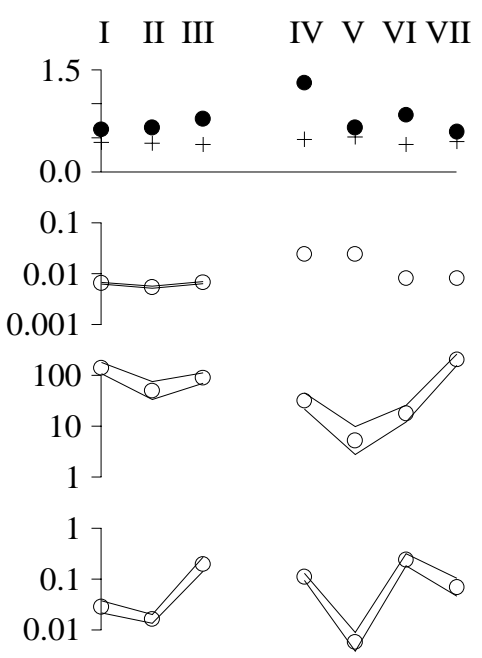

Non-weathered horizontal

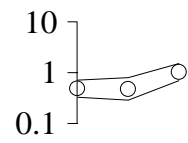

\section{Specific yield Oxidized}

Reduced
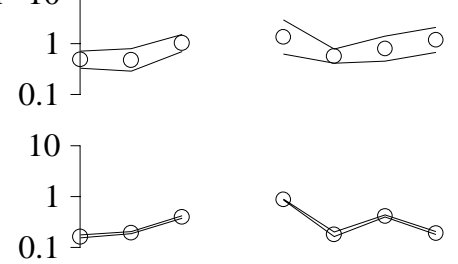

$$
\text { vertical }
$$
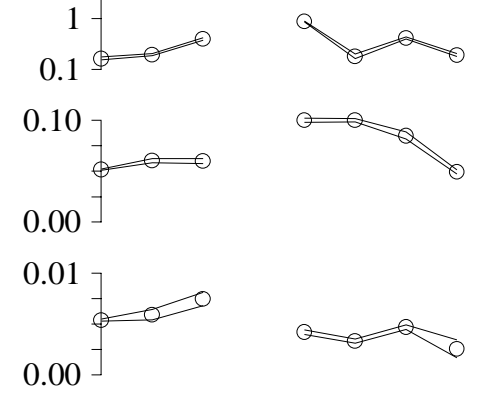

Fig. 5. Seven calibrations of groundwater parameters for the overburden, with $95 \%$ linear confidence band to indicate solution sensitivity. 
last or the last iteration in the sequential calibration ( $I V$ and $V I)$, or weight discharge data ten times more than Eqn. 2 (III, $V$ and $V I I)$.

The drain time and the vertical conductivity of the nonweathered overburden are almost fully resolved with their own eigenvector, in contrast with the conductivity and specific yield of the reduced till. The explanation is that the first two parameters govern the topographical and vertical diversion, while the last two parameters affect the transition regime only. Deliberately keeping the drain time at the larger value of the second last iteration in the sequential calibration implies smaller vertical diversion and, thus, smaller conductivity in the surrounding oxidized till. Extra weight on discharge data emphasises storm flow at the expense of base flow. The result is a faster draining time or, if held constant, a smaller vertical conductivity of the nonweathered overburden and smaller parameters in the reduced till. Calibration VII is selected because it matches the water table data best, while the discharge data vary little between the calibration runs. Water table data guide calibration around the thresholds arising from the drain level and the layer interfaces, but the improved match over a free drain time (II) underlines that the reduced till parameters are slightly ill-posed and not captured by the linear uncertainty interval around each calibration.

Table 1 shows that drain time and, to some extent, the estimated conductivity of the surrounding oxidized till, change significantly with calibration. The reduction of the drain time by a factor of almost 30 comes from a model difference. In the stream flow separation (Schrøder, 2003) the flow was restricted to be vertical 1D above the drain level. In the $3 \mathrm{D}$ groundwater model, the surface at the midline is ten times farther away from the drain line than the surface right above, and circulation extends into the low permeability reduced till. Figure 6 shows how the groundwater module simulates the stream flow components

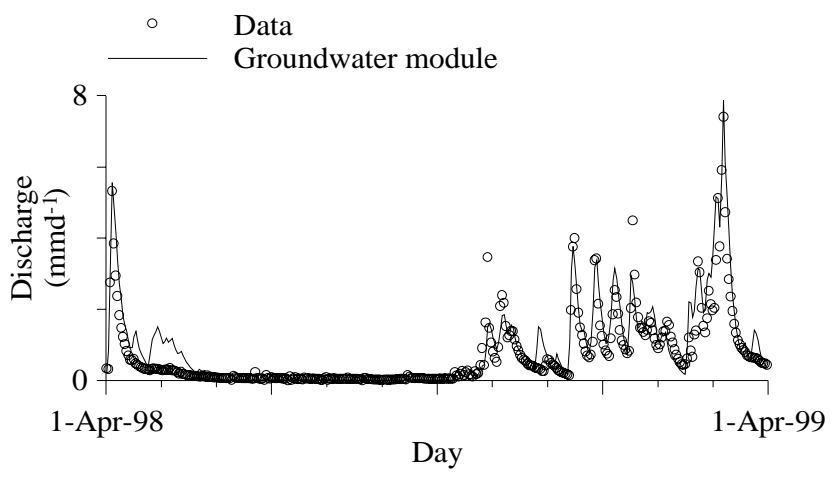

Fig. 6. Catchment discharge simulated with the calibrated groundwater module against measured less contribution from waterworks, sewage and pavement. of drainage flow and base flow. The spurious peaks in early May, early December and late March arise from the a priori mapping of recharge, where the number of wells sufficed only for a monthly resolution of the time-varying area contributing to drainage. The peaks in late October and in mid-January arise from convective rainfall not captured by the rain gauge. Redistribution from the prior mapping does not affect the annual recharge to a degree that could disqualify usage of the model on an inter-annual basis. Apart from that, the representation of drains by a single linear reservoir, the degree-day model for snow storage and the merging of preferential conduits into a weathered anisotropy ratio appear to be successful for modelling of the catchment water balance. Whether the simulation error in the water table of one-tenth of the seasonal amplitude will misrepresent the capillary rise depends on the non-linear retention curve. The following section elaborates on that.

\section{Unsaturated module}

The unsaturated module solves Richards' equation for vertical flow. Vegetation characteristics from Christiansen et al. (2004) and unsaturated characteristics from Carsel and Parrish (1988) apply, but MIKE SHE extends van Genuchten's (1980) parameterisation of the retention curve to conductivity with Kozeny's approach (Averjanov, 1950) instead of a priori used direct linkage of Mualem (1976). This adds Kozeny's exponent to the parameters needed for model calibration.

For log tensions equally spaced from wilting either up to or including the toe at saturation, Fig. 7 shows two different least-square fits of Kozeny's exponent to Mualem's
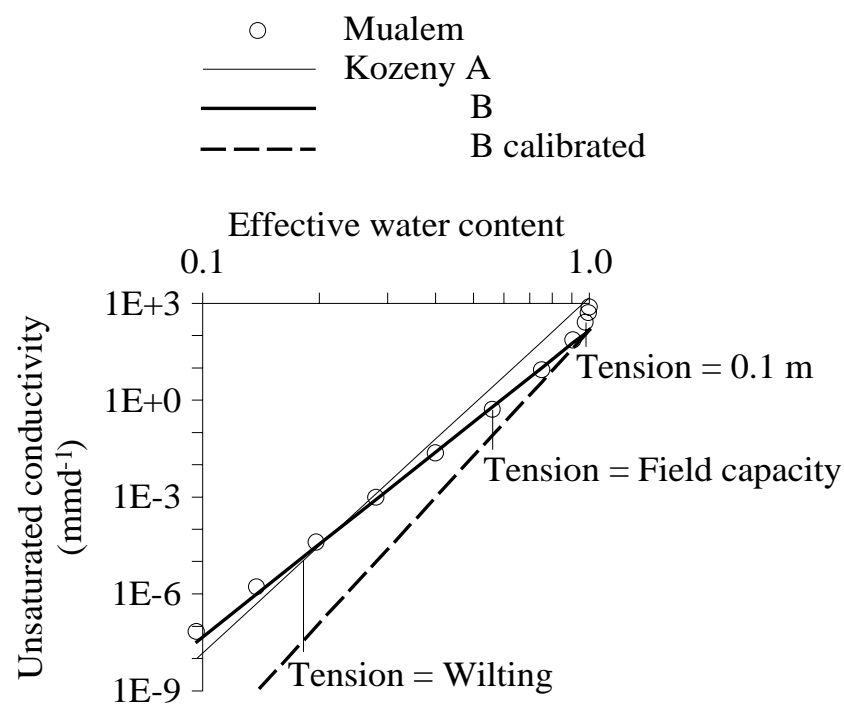

Fig. 7. Kozeny's exponent fitted to Mualem's expression between wilting and either saturation (A) or to $0.1 \mathrm{~m}$ tension (B). The case shown is the topsoil. 
parameterisation given in the soil database. Omitting the toe necessitates a reduction in the saturated conductivity by one order of magnitude. A tight fit to the database values is not, therefore, possible in strata where either dryness or near-saturated conditions prevail. How the two fits should be combined is examined by running the model until it reproduces the mean discharge and the minimum water table. Simulation over the wet to dry 1981-92 circumvents possible bias during the wet monitoring period. The model is started from the previous initial guess on the water table, with the moisture content in the unsaturated zone equal to field capacity and three years of identical weather to eliminate any impact of the initial conditions. One run for spring barley and one run for winter wheat are carried out and weighted, as mentioned previously. The first three combinations in Table 2 show that excluding the toe helps reproduce discharge, but the improvement becomes marginal if the corresponding dry state is assumed to prevail below the topsoil. Further improvement is obtained in the next four combinations by copying Kozeny's exponent from the stratum below (Jensen and Refsgaard, 1989), but the inadequate seasonal amplitude in the water table emphasises that the capillary rise maintains a wet state below the topsoil. This observation leads to the selected approach, given in the last combination, where calibration has little impact on the fit to the water table.

Compared with laboratory values in the soil database, an up to two orders of magnitude underestimation is found in the topsoil conductivity (Fig. 7). What causes such a 'scalar effect'? Ploughing generates a pan at the base of the furrows. An alternative to the suggested calibration could be to add a plough pan in a depth of $0.25-0.3 \mathrm{~m}$, but even a three orders of magnitude smaller conductivity does not affect the discharge. The underestimation in the topsoil during summer is merely balancing the overestimation in the thick weathered till below during the spring and autumn, when this part of the soil profile comes within the toe at saturation. While the origin of the effect seems to be seasonal rather than scalar, it remains unclear how much of the effect MIKE SHE would be able to eliminate with an implementation of Mualem's linkage. Hysteresis may also contribute to the discrepancy, but the applied soil database and model offer no means for a further investigation. Hypothetically, the averaging of drying and wetting scan curves will shift the capillary rise towards the autumn. Table 2 shows that the balance between discharge and the summer water table remains intact, so the average of the intimately related capillary rise cannot be greatly affected on inter-annual timescales.

\section{Results and discussion}

The simulations cover the period September 1980, where the well that monitors the annual trend in aquifer head before the mid-nineties was installed in Flakkebjerg, to the end of monitoring in August 1999. Table 3 shows that the annual water balance calculated for spring barley is little different $(9 \mathrm{~mm})$ from that of winter wheat, so that the gradual substitution of spring barley with winter wheat (Fig. 3) is unlikely to be significant. This justifies using a fixed proportion of the two crops throughout the modelling period. The insensitivity arises from the shallowness of the water

Table 2. Kozeny's exponent for unsaturated conductivity in the weathered strata calibrated 1981-92 against discharge less contribution from waterworks, sewage and pavement (Q) and the deepest monthly water table in well 1 against August 1998 (h).

\begin{tabular}{llllll}
\hline & Topsoil & Oxidized & Reduced & Q(mm/y) & h(m depth) \\
\hline Measured & & & & 231 & 3.7 \\
Tension a & A & A & A & 192 & \\
& B & A & A & 202 & \\
& B & B & A & 203 & \\
Layer below $^{\text {b }}$ & B & A(n) & A & 208 & 2.3 \\
& B & B(n) & A & 206 & 2.4 \\
& A(n) & A & A & 205 & 3.5 \\
Final & B(n) & A & A & 212 & 3.3 \\
& B(n=13) & A & A & 232 & 3.3
\end{tabular}

${ }^{\mathrm{a}}$ Fit to Mualems's expression between wilting and $(A)$ saturation or $(B) 0.1 \mathrm{~m},{ }^{\mathrm{b}}$ value in parenthesis from layer below. 


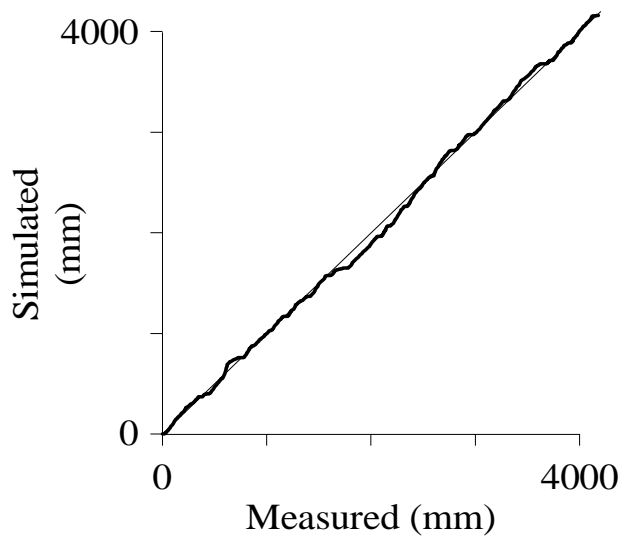

Figure 8. Catchment discharge 1981-99 simulated with the integrated model against the measured less contribution from waterworks, sewage and pavement.

table in winter that allows the capillary rise to fully compensate the soil drying generated by solar heating. Transmission through evaporation from bare fields before the sowing of spring barley is close in efficiency to the transpiration from winter wheat with rudimentary rooting. The bulk of recharge to the water table is diverted to the stream by the tile drains (Fig. 2). Tile drains shorten the period of waterlogging of the surface but the hydraulic gradient through the thick overburden is barely reduced. It is the density of the overburden that forms the barrier against replenishment of the aquifer below. The $31 \mathrm{~mm} \mathrm{yr}^{-1}$ of aquifer recharge compares with $22 \mathrm{~mm} \mathrm{yr}^{-1}$ in the $450 \mathrm{~km}^{2}$ Tude catchment to the north-west (Christensen, 1994); the $39 \mathrm{~mm} \mathrm{yr}^{-1}$ in the $65 \mathrm{~km}^{2}$ Bjerge catchment to the south (Christiansen et al., 2004), and the $28 \mathrm{~mm} \mathrm{yr}^{-1}$ for the 7215 $\mathrm{km}^{2}$ Zealand as a whole (Geological Survey of Denmark and Greenland, 1999). Figure 8 shows that simulated stream flow deviates only $0.4 \%$ from the measured sum. The largest discrepancy is seen from September to November 1987, when construction works redirected runoff from paved areas outside the catchment to the stream.

\section{RUNOFF}

The a priori recharge mapping applied the variable source concept to identify the extent of the area where the water table is shallow enough to trigger drainage flow, the main contributor to stream flow. All water table wells supported the assumption that the contributing area is a continuum expanding uphill from the stream, consistent with gravity being the dominating mechanism and uniform rainfall. The concept is considered valid if the runoff coefficient, defined as the stream flow volume divided by the catch (total event precipitation), varies proportionally with the catch. Myrabø (1997) found this to be the case in glacial till. Precipitation
Table 3. The water balance of 1981-99, weighting the model run for spring barley (B) two-thirds and the model run for winter wheat (W) one-third.

\begin{tabular}{|c|c|c|c|}
\hline & $B$ & $W$ & Total \\
\hline \multicolumn{3}{|l|}{ Precipitation $\left(\mathrm{mm} \mathrm{y}^{-1}\right)$} & 736 \\
\hline \multicolumn{3}{|c|}{ Potential evapotranspiration $\left(\mathrm{mm} \mathrm{y}^{-1}\right)$} & 557 \\
\hline Evapotranspiration $\left(\mathrm{mm} \mathrm{y}^{-1}\right)$ & 486 & 495 & 489 \\
\hline Canopy (\%) & 13 & 23 & 17 \\
\hline Pond $(\%)$ & 0 & 0 & 0 \\
\hline Evaporation (\%) & 54 & 30 & 46 \\
\hline Transpiration (\%) & 33 & 47 & 38 \\
\hline Groundwater (\%) & 0 & 0 & 0 \\
\hline Net recharge $\left(\mathrm{mm} \mathrm{d}^{-1}\right)$ & 247 & 238 & 244 \\
\hline Aquifer replenishment $\left(\mathrm{mm} \mathrm{d}^{-1}\right)$ & 31 & 31 & 31 \\
\hline Discharge $\left(\mathrm{mm} \mathrm{d}^{-1}\right)$ & 222 & 212 & 219 \\
\hline
\end{tabular}

is an acceptable approximation to net recharge during winter storms, but not over the whole year due to the influence of evapotranspiration. Annual evapotranspiration does not sum up proportionally to area, because the capillary rise depends non-linearly on the water table depth. Annual net recharge can instead be approximated as the diversion of groundwater to the stream plus the one order of magnitude smaller aquifer replenishment, cf. Table 3.

Figure 9 presents simulated annual volumes for the study catchment. The division at September 1, when monthly stream flow has its minimum, reduces the scatter around strict proportionality caused by the lag in base flow and the lag between precipitation and recharge in late summer. A similar proportionality in the other fully underdrained clayey catchments ranging two orders of magnitude in size and steepness implies that MIKE SHE's merging of weathered strata, lumping of drain schemes and seasonally problematic unsaturated conductivity are of minor importance when inferring statistics for the annual water balance. Note that the range of runoff coefficients reveals a high variability of the contributing area, reflecting the inter-annual variability in weather.

\section{NET RECHARGE}

Winter (1999) outlined qualitatively why net recharge adjusts to topography most of the time, and Levine and Salvucci (1999) made a statistical approach based on this observation. Firstly, they used steady-state unsaturated modelling on an idealised hill slope cross-section to relate net recharge to the water table depth for a particular atmospheric forcing. The model was run for a number of scenarios to establish a long-term correlation that covered all conceivable forcing. Secondly, they used the correlation to furnish a groundwater model with a lookup table for any 


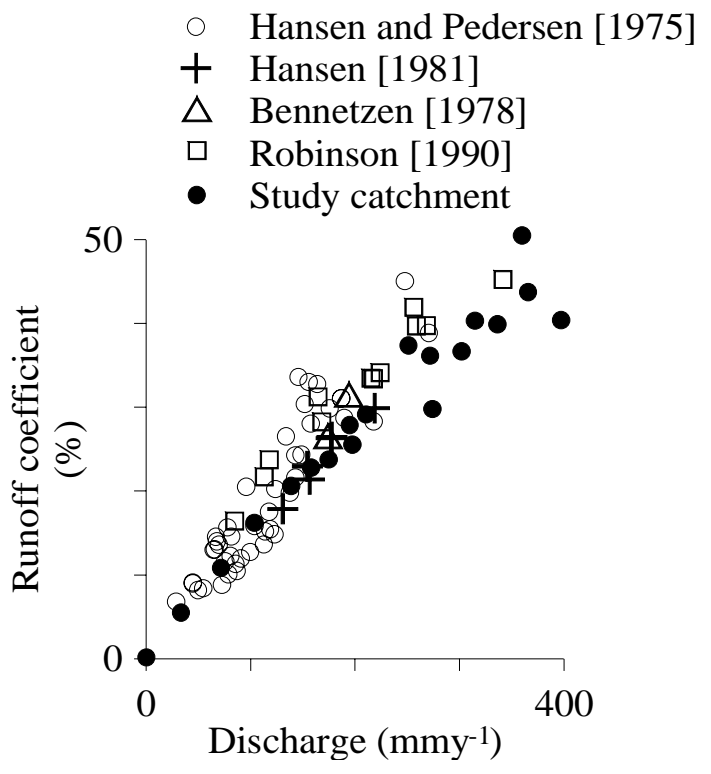

Fig. 9. Annual discharge versus annual runoff coefficient, defined as discharge divided by precipitation. Simulation of the study catchment against measurement from other underdrained clayey catchments.

entry of the water table depth. The model was iterated in steady-state to an all-time mean distribution of net recharge against terrain level.

Two years of monitoring cannot provide a good estimate of the long-term mean water table level, but the execution of the established integrated model over the one order of magnitude longer time frame comes close. Figure 10 presents the corresponding average net recharge in every model grid across the catchment. Evidently, the anticipated uphill increase in net recharge is found. The mean $244 \mathrm{~mm} \mathrm{yr}^{-1}$ reflects the precipitation surplus in high-latitude humid, temperate areas, in this case without impermeable bedrock to raise the water table and increase the capillary rise. While the capillary rise reaches only $20 \mathrm{~mm} \mathrm{yr}^{-1}$ at the water divide, the groundwater focus maintains $90 \mathrm{~mm} \mathrm{yr}^{-1}$ in the stream valley. Figure 10 shows that the difference fully explains the change in net recharge.

The scatter above the stream valley illustrates that the smooth flow of groundwater below the undulating terrain generates a variety of average water table depths at all terrain levels. The increase in net recharge uphill reflects an increasingly frequent development of zero-flux planes in the unsaturated zone, cancelling the capillary rise from the water table. Dry years aggravate the soil moisture deficit, which drags the area subject to capillary rise uphill in summer and postpones the water table rise at the onset of winter. Uphill areas are free of capillary rise for the most time, leading to higher net recharge. In dry years, this area

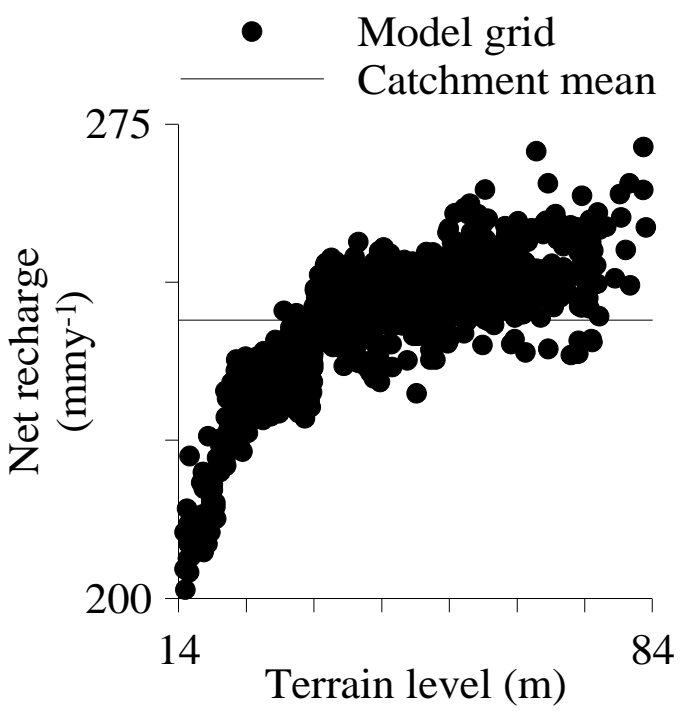

Fig. 10. Simulated net recharge average for 1981-99 in every model grid across the catchment and the total mean.

is reduced, and vice versa in wet years. How strong the natural feedback to atmospheric forcing is in clay is reflected in the proportionality of the wet drainage area shown in Fig. 9.

\section{EVAPOTRANSPIRATION}

The model output for the annual water balance maps the catchment response, in terms of evapotranspiration and discharge, to two decades of weather patterns. The barotropic, meridional oscillation in atmospheric mass between the Icelandic low pressure and the Azores high pressure has been designated the North Atlantic Oscillation (NAO). NAO shifts the latitude of the winter storm track and the associated eddy activity that carries most of the moisture precipitating as frontal rain over Europe, and accounts for one-third of the variability in the North Atlantic sea level. Hurrell (1995) proposed an index for the NAO based on the mean sea level difference in winter between two specific stations in Iceland and Portugal to summarise the state of the recurrent oscillation. His index enabled the meteorological community to trace the oscillation back to 1864 , far beyond the 1950 s reached by reanalysis of numerical weather prediction models. Reanalysis, on the other hand, assimilates such a large volume of data that the noise reduction undoubtedly allows for better detection of annual trends. Re-analysis shows a NAO dipole not always centred in the vicinity of the two stations considered, making the first principal component of wintertime sea level in the North Atlantic sector a better index (Marshall et al., 2001). Thompson and Wallace (1998) had found the same quantity 
to be coupled to the surface temperature over Eurasia rather than the NAO index. A similar observation for the polar vortex made them suggest an Arctic Oscillation, in which the land-sea contrast induces baroclinic instability in both surface temperature and air pressure. Their concept of an inter-annual oscillation covering the entire northern hemisphere instead of just the Atlantic sector has revived the debate on the driving mechanism behind the weather pattern noted for so long over Europe.

The power spectrum of the NAO shows a maximum around the 2-3 year mode and a positive trend in the decadal mode over the past few decades. Figure 11 presents the simulated evapotranspiration and discharge on an annual basis, enough to resolve the dominant part of the spectrum, against the NAO index and the reanalysis alternative from the National Center for Atmospheric Research. Although reanalysis deviates due to different coverage, noise level and reference period for normalisation, the correlation between the reanalysis-based index and original index is $91 \%$ and the sign in the annual trend is consistent, apart from 1993-94 and 1997-98. Evapotranspiration and discharge deviate from the original index in the sign of the annual trend as many as five and nine times, respectively, in part the reason for their correlation with the index being just 30 and 32\%. Hurrell and van Loon (1997), who mapped the spatial extent of NAO using the correlation with centurylong precipitation records, placed Denmark in the trough between positive correlation in Scandinavia and negative in continental Europe based on the $14 \%$ correlation found for the Danish rain gauge used. Two decades of catchment modelling cover a much shorter period, but the number of repetitions of the dominant 2-3 year mode and the sheer size of the catchment relative to the tiny orifice of a rain gauge make the larger catchment-based correlation more reliable.

Evapotranspiration is the latent heat transport balancing net radiation and sensible heat transport. On clayey soils with a shallow water table, capillary rise can extract sufficient soil moisture to keep evapotranspiration near its potential limit. Near the limit, evapotranspiration depends monotonically on surface temperature, except for a minor modification by air vapour pressure. The almost monotonic dependence remains valid for all weather conditions, so that evapotranspiration should reflect the correlation between surface temperature and atmospheric pressure, specifically the presence of a long-term oscillation. Rainfall measurements have been used to correlate soil moisture with the atmospheric pressure field. Hurrell and van Loon (1997) utilised the fact that the variance between storms reflecting the balance between transport and storage of latent heat is of minor importance at timescales much longer than the

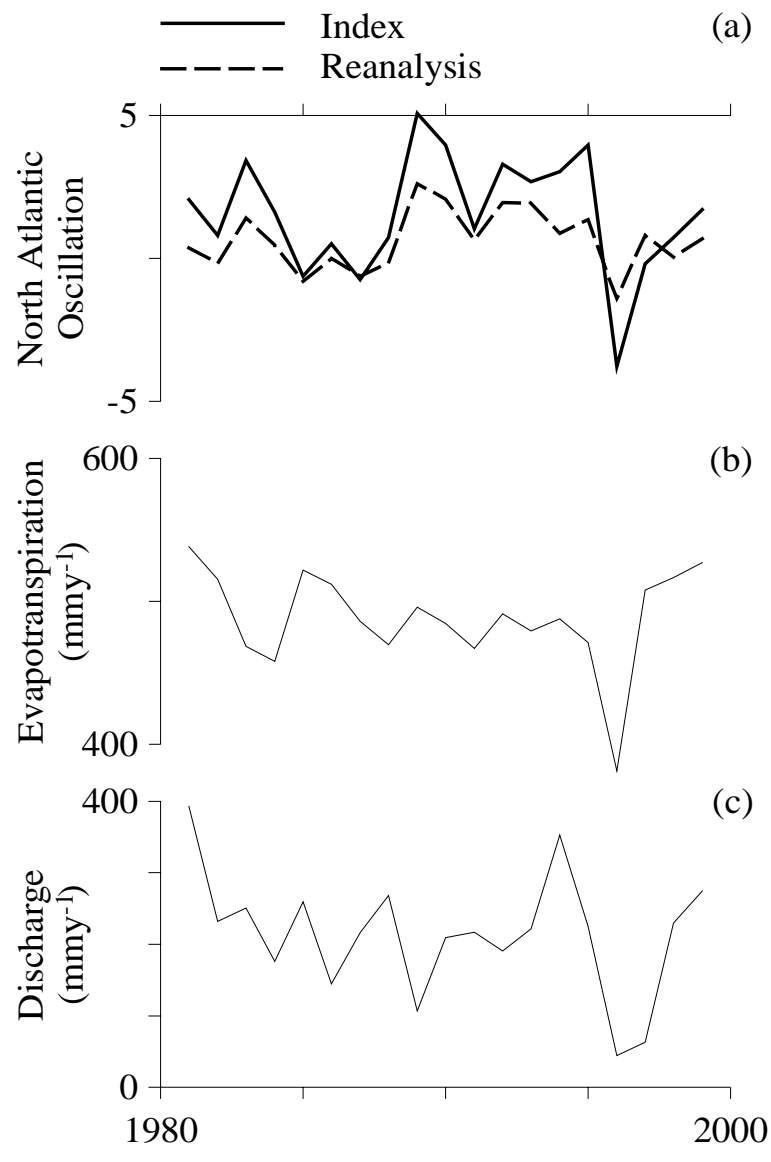

Fig. 11. Simulated evapotranspiration and discharge against the North Atlantic Oscillation given by its index and the first principal component of the sea level pressure in reanalysis (http:// www.cgd.ucar.edu / jhurrell/nao.pc.winter.html).

return period of the storms. A data set representing large areas and timescales is closer to 'ground truth', if it can take into account that soil moisture is governed more by capillary rise (or lack of it) than by the catch during storms. Evapotranspiration from clayey soils is, therefore, expected to offer the best record for unveiling the presence of an atmospheric oscillation.

Rainfall, as integrated in discharge, correlates to the NAO just as well as evapotranspiration, but the doubling in years with a deviating trend sign suggests that the base flow lag in addition to the unsaturated zone lag will disqualify rainfall in the long run. Integrated modelling of evapotranspiration from various clayey catchments throughout northern midto high latitudes seems to be a new way of mapping the spatial extent of the oscillation. Going further back than reanalysis will be feasible, if records can be provided for rainfall, discharge, temperature and cloud cover, as a proxy for radiation, and information on anthropogenic changes in stream flow and plant coverage is available (Schrøder, 2003). The efforts towards a regional map with many catchments 
could be minimised by modelling only suitable 'anchor' catchments. In the intermediate catchments, the annual evapotranspiration could be calculated as rainfall less discharge and aquifer replenishment from regional groundwater modelling.

\section{Conclusions}

The integrated model MIKE SHE has been used to explore how the groundwater feedback to evapotranspiration, referred to as capillary rise, influences the water balance of a $16 \mathrm{~km}^{2}$ clayey catchment in Denmark. Over two years, detailed measurements were taken from three internal discharge gauging stations, eleven groundwater wells, five piezometers and a recording rain gauge. A conceptual geological model was set up based on campaigns of electrical sounding and slug tests. Also, the development of vegetation was surveyed. Automatic calibration of the groundwater module using the code Pest and a priori values of parameters and net recharge obtained from the monitored years resulted in satisfactory simulation, despite signs of ill-posedness in the deepest weathered stratum. The drain time constant changed significantly because 1D flow had been assumed a priori. In the unsaturated module, manual calibration of Kozeny's approach to conductivity using the Mualem relation for soil water retention was successful.

Integrated modelling over two decades reproduces a replenishment rate of the regional aquifer similar to that found elsewhere on Zealand. All main features of runoff were captured, in particular the contribution from the area with a water table above the drain level. The model demonstrates dynamically that capillary rise accounts for an uphill increase in net recharge amounting to, on average, $30 \%$. Furthermore, the $30 \%$ correlation found between annual evapotranspiration and the North Atlantic Oscillation supports the hypothesis of an Arctic Oscillation. The combination in this hypothesis of atmospheric pressure and surface temperature suggests that evapotranspiration is a better measure than rainfall to characterise the oscillation. The use of historical records from clayey catchments to further investigate this matter is encouraged.

\section{Acknowledgments}

The authors wish to thank the Technical University of Denmark for funding the research by a Ph.D. scholarship and the two anonymous reviewers for their comments.

\section{References}

Allerup, P. and H. Madsen, 1980. Accuracy of point precipitation measurements. Nord. Hydrol., 11, 57-70.

Averjanov, S.F., 1950. About permeability of subsurface soils in case of incomplete saturation. Engineering Collection, 7, 1921.

stofbalance ved optimal planteproduktion, 3. Modeller og resultater (Danish). Tidsskrift for planteavl, 82, 191-220.

Bergström, S., Bøggild, C., Einarsson, K., Gjessing, Y., Sand, K., Sælthun, N., Thomsen, T. and Vehviläinen, B., 1993. Snow modelling, water resources, climate change. Proceedings, 9th Int. Northern Research Basins Symposium/Workshop, Canada, NHRI Symposium No. 10, Ed. T. Prowse, C. Ommanney, K. Ulmer, 1-13.

Carrera, J. and Neuman, S.P., 1986. Estimation of aquifer parameters under transient and steady-state conditions, 1. Maximum likelihood method incorporating prior information. Water Resour. Res., 22, 199-210.

Carsel, R.F. and Parrish, R.S., 1988. Developing joint probability distributions of soil water retention characteristics. Water Resour. Res., 24, 755-769.

Christensen, S., 1994. Hydrological model for the Tude å catchment. Nord. Hydrol., 25, 145-166.

Christensen, S. and Cooley, R.L., 1999. Evaluation of prediction intervals for expressing uncertainties in groundwater flow model predictions. Water Resour. Res., 35, 2.627-2.639.

Christiansen, J.S., M. Thorsen, M., Clausen, T., Hansen, S. and Refsgaard, J.C., 2004. Modelling of macropore flow and transport processes at catchment scale. J. Hydrol., 299, 136158.

DHI, Water \& Environment, 1999. MIKE SHE 1999 Water movement, User manual, Denmark.

Doherty, J., 1999. Pest, model-independent parameter estimation, Watermark Computing, Brisbane, Australia.

Duan, Q., Sorooshian, S. and Gupta, V., 1992. Effective and efficient global optimization for conceptual rainfall-runoff models. Water Resour. Res., 28, 1.015-1.031.

Geological Survey of Denmark and Greenland, 1999. National vandressource model, midtvejsrapport, Status - maj 1999 (Danish), Denmark.

Gerber, R.E. and Howard, K., 2000. Recharge through a regional till aquitard: three-dimensional flow model water balance approach. Ground Water, 38, 410-422.

Halford, K.J., 1999. Effects of steady-state assumption on hydraulic conductivity and recharge estimates in a surficial aquifer system. Ground Water, 37, 70-79.

Hansen, B., 1981. Drcenvandskvantitet og kvalitet i Susåens opland (Danish), Rep. Suså H 19, Danish Committee for Hydrology, Denmark.

Hansen, L. and Pedersen, E.F., 1975. Drænvandsundersøgelser 1971-74 (Danish), Tidsskrift for planteavl, 79, 670-688.

Hinton, M.J., Schiff, S.L. and English, M.C., 1993. Physical properties governing groundwater flow in a glacial till catchment. J. Hydrol., 142, 229-249.

Hurrell, J.W., 1995. Decadal Trends in the North Atlantic Oscillation: Regional Temperatures and Precipitation. Science, 269, 676-679.

Hurrell, J.W. and van Loon, H., 1997. Decadal variations in climate associated with the North Atlantic Oscillation. Climatic Change, 36, 301-326.

Isaaks, E.H. and Srivastava, R.M., 1989. Applied geostatistics, Oxford Univ. Press, New York, USA. 
Jensen, K. H. and J. C. Refsgaard, 1989. Spatial variability of soil physical parameters, theoretical and experimental analyses. VI: Modelling of water flow and solute transport in soil profiles and over field areas Danish Agricultural and Veterinary Research Council, Denmark.

Lerner, D.N., Issar, A.S. and Simmers, I., 1990. Groundwater recharge, a guide to understanding and estimating natural recharge. Int. Contributions to Hydrogeology, 8, Int. Ass. Hydrogeologists, Verlag Heinz Heise, Hannover, Germany.

Levine, J.B. and Salvucci, G.D., 1999. Equilibrium analysis of groundwater-vadose zone interactions and the resulting spatial distribution of hydrologic fluxes across a Canadian prairie. Water Resour. Res., 35, 1.369-1.383.

Malik, R.S., Kumar, S. and Malik, R.K., 1989. Maximal capillary rise flux as a function of height from the water table. Soil Sci. J.5, 148, 322-326.

Marshall, J., Kushnir, Y., Battisti, D., Chang, P., Czaja, A., Dickson, R., Hurrel, J., McCartney, M., Saravana, R. and Visbeck, M., 2001. North Atlantic climate variability phenomena, impacts and mechanisms. Int. J. Climatology, 21, 1.863-1.898.

McCartney, R. Saravanan and M. Visbeck, 2001. North Atlantic climate variability phenomena, impacts and mechanisms. Int. J. Climatol., 21, 1.863-1.898.

Mikkelsen, H.E. and Olesen, J.E., 1991. Sammenligning af metoder til bestemmelse af potentiel fordampning (Danish). Rep. S 2157 , Danish Institute of Agricultural Sciences, Denmark.

Mualem, Y., 1976. A new model for predicting the hydraulic conductivity of unsaturated porous media. Water Resour. Res., 12, 513-522.

Myrabø, S., 1997. Temporal and spatial scale of response area and groundwater variation in till. Hydrol. Process., 11, 1.861-1.880.
Prathapar, S.A. and Meyer, W.S., 1993. Measurement and estimation of capillary upflow from watertables under maize on irrigated soils. Aus. J. Soil Res., 31, 119-130.

Rango, A. and Martinec. J., 1995. Revisiting the degree-day method for snowmelt computations. Water Resour. Bull., 31, 657-669.

Schrøder, T.M., 2003. Groundwater recharge and capillary rise in a clayey till catchment, $\mathrm{PhD}$ Thesis, Environment \& Resources DTU, Technical University of Denmark.

Statistics Denmark, 1986-99. Agricultural statistics annuals, Copenhagen, Denmark

Thompson, D.W.J. and Wallace, J. M., 1998. The Arctic Oscillation signature in the winter geopotential height and temperature fields. Geophys. Res. Lett., 25, 1.297-1.300.

van der Kamp, G. and Maathuis, H., 1991. Annual fluctuations of groundwater levels as a result of loading by surface moisture. J. Hydrol., 127, 137-152.

van Genuchten, M.T., 1980. A closed-form equation for predicting the hydraulic conductivity of unsaturated soils. Soil Sci. Soc. Amer. J., 44, 892-898.

Waagepetersen, J., Clausen, S.U., Schlünsen, K., Clark, D.R., Olesen, J.E. and Mikkelsen, H.E., 1991. Drainage and runoff in 9 minor water courses from the 1920's until today (English summary). Rep. 48, Danish Land Development Service, Denmark.

Wigmosta, M.S. and Burges, S.J., 1997. An adaptive modeling and monitoring approach to describe the hydrologic behavior of small catchments. J. Hydrol., 202, 48-77.

Winter, T.C., 1999. Relation of streams, lakes, and wetlands to groundwater flow systems. Hydrologeol. J., 7, 28-45. 